\title{
Uma revisão da disponibilidade de dados ecológicos visando o direcionamento de novas pesquisas na Lagoa do Peri
}

\author{
Letícia Frozza Teive \\ Leonardo Kleba Lisboa \\ Maurício Mello Petrucio* \\ Departamento de Ecologia e Zoologia, CCB, Universidade Federal de Santa Catarina \\ Campus Universitário, Trindade, CEP: 88010-970, Florianópolis - SC, Brasil \\ *Autor para correspondência \\ petrucio@ccb.ufsc.br
}

Submetido em 25/07/2007

Aceito para publicação em 09/04/2008

\section{Resumo}

O aumento do contingente populacional, bem como da demanda pelo recurso hídrico, têm intensificado as ações humanas na região da bacia da Lagoa do Peri. Este trabalho realizou uma revisão da disponibilidade de dados ecológicos da Lagoa do Peri, visando o direcionamento de novas pesquisas para a compreensão do funcionamento do ambiente. Estas informações podem contribuir na elaboração de uma futura proposta de conservação e uso sustentável da Lagoa. Alta densidade de cianobactérias Cylindrospermopsis raciborskii foi diagnosticada nas águas da Lagoa, e apresenta-se como situação de risco para a saúde do ecossistema e conseqüentemente da população. Destacam-se lacunas a respeito da dinâmica, funcionamento e estruturação das comunidades aquáticas, suas relações com o entorno e a influência de fatores abióticos. Séries de dados contínuos ao longo do tempo também são informações ausentes. Percebe-se a necessidade de medidas educacionais, políticas e sociais na conservação do ambiente, voltadas para o manejo e uso sustentável da bacia da Lagoa do Peri. Estas práticas garantirão a qualidade e disponibilidade do recurso hídrico para esta e as futuras gerações.

Unitermos: Lagoa do Peri, conservação, lagoas costeiras, síntese ecológica, qualidade de água

\section{Abstract}

A review on the availability of ecological data aiming new researches in Peri lagoon. The increase in population as well as the water resource demand has been intensifying the human influence in Peri Lagoon basin. A review on the availability of data concerning the ecology of Peri Lagoon was made, aiming at the development of new researches to understand the functioning of this ecosystem. This information can contribute to the elaboration of a conservation proposal and sustainable use of the Lagoon in the future. High cyanobacteria density (Cylindrospermopsis raciborskii) was detected in the Lagoon waters, which happens to be a risky situation for the ecosystem's health and consequently for the population. The review highlights a lack of available information about the dynamics, functioning and structure of aquatic communities, as well as their relationships with the surrounding area and the influence of abiotic factors. Series of continuum data with respect to time are also considered to be lacking. Educational, political and social practices in environmental conservation are necessary, aiming at the management and sustainable use of Peri Lagoon basin. These practices will guarantee water resource quality and availability for the current and future generations.

Key words: Peri lagoon, conservation, coastal lagoon, ecological review, water quality 


\section{Introdução}

A Lagoa do Peri constitui o maior corpo de água doce da Ilha de Santa Catarina. Está rodeado nas suas porções norte, oeste e sul por denso remanescente de Floresta Atlântica, e na porção leste por restinga típica de vegetação litorânea separando a Lagoa do Oceano Atlântico (Silva, 2000). Esta Lagoa costeira, como as demais ocorrentes ao longo do litoral brasileiro, compreendem um dos principais sistemas lênticos do país, tendo origem através do isolamento de enseadas e pequenas baias por cordões de areia (Esteves, 1988).

O Parque Municipal da Lagoa do Peri foi delimitado com o intuito de preservar os atributos excepcionais da natureza a fim de conciliar a proteção dos ecossistemas (rios, lagoa, restinga, mata) com práticas educacionais, científicas e recreativas que envolvam a comunidade local, sendo proibida qualquer atividade de exploração dos recursos naturais (Lei 1828/81 Dec. 091/82, apud CECCA, 1997). Em contraponto com isso, a Lagoa vem sendo utilizada como água de abastecimento para o sul da Ilha.

Com o aumento do contingente populacional na porção sul da ilha, há consequentemente aumento na demanda por água potável, intensificando as atividades humanas na região da Lagoa do Peri. Essa prática, apesar de benéfica do ponto de vista sócio-econômico, acaba interferindo nos padrões naturais do corpo d'água alterando seus ciclos, o que pode levar ao esgotamento do ecossistema, perda da biodiversidade, e consequentemente, perda da qualidade da água. Os impactos ambientais nos ecossistemas aquáticos têm diferentes origens e formas, mas na maioria das vezes estão associados a uma ação antrópica, como lançamento de efluentes industriais e domésticos, alteração nos cursos e níveis d'água, retirada da vegetação ripária, entre muitos outros fatores que contribuem para o desgaste e consequentemente para a má qualidade dos corpos d'água.

O conhecimento a respeito da bacia da Lagoa do Peri apesar de ainda incipiente, aumentou consideravelmente nos últimos anos (NEMAR, 1999; Pereira, 2001; Simonassi, 2001; Oliveira, 2002; Penteado, 2002). Contudo, ainda existem algumas lacunas do conhecimento sobre a estrutura e funcionamento da Lagoa. $\mathrm{Na}$ comunidade fitoplanctônica foi revelado a presença de cianobactérias associadas à produção de cianotoxinas (Laudares-Silva, 1999; Matthiensen e Barbosa, 2003, Grellmann, 2006), um fator preocupante, que entre outros demonstra a importância e necessidade de haver uma política de gestão ambiental voltada para o desenvolvimento sustentável e ecologicamente viável, com efetivo manejo dos recursos naturais, aliado à conscientização e envolvimento da comunidade local.

As comunidades biológicas também são fundamentais na caracterização de um corpo aquático, pois refletem a integridade ecológica dos ecossistemas, integrando os efeitos dos diferentes agentes impactantes e fornecendo uma medida agregada dos impactos (Barbour et al., 1999). A avaliação da diversidade de hábitats é também uma importante ferramenta na avaliação de condições ambientais de ecossistemas aquáticos, devido à forte relação entre sua disponibilidade e a biodiversidade aquática (Barbosa et al., 2000).

As interações entre organismos e populações (intra e interespecíficas) devem ser bem conhecidas e utilizadas como uma ferramenta para a compreensão da sustentabilidade da biodiversidade (Barbosa, 1994). Embora conhecidos, esses dados têm sido pouco explorados ou abordados de forma isolada em estudos sobre os ambientes aquáticos realizados no Brasil, o que o gera muitas lacunas no conhecimento acerca de sua estrutura e funcionamento do ecossistema aquático como um todo.

Em virtude destes fatos, surgiu à iniciativa de reunir informações que se encontram dispersas e fragmentadas, compilando dados sobre a estrutura, composição, função e funcionamento da Lagoa do Peri, visando à estruturação de um acervo sobre este ambiente, além de facilitar a identificação de prioridades para a manutenção da saúde do ecossistema. Este trabalho realizou uma revisão da disponibilidade de dados ecológicos da Lagoa do Peri, visando o direcionamento de novas pesquisas para a compreensão do funcionamento do ambiente. Estas informações podem contribuir na elaboração de uma futura proposta de conservação e para o uso sustentável desta Lagoa. 


\section{Material e Métodos}

\section{Área de estudo}

A bacia hidrográfica da Lagoa do Peri compõe o Sistema de Bacias Isoladas da Vertente Atlântica (Santa Catarina, 1997). O Parque Municipal da Lagoa do Peri (Figura 1) está localizado ao sul da Ilha de Santa Catarina, entre as coordenadas $27^{\circ} 42^{\prime} 30^{\prime \prime}$ e $27^{\circ} 46^{\prime} 30^{\prime \prime}$ de latitude Sul e 48 $30^{\circ} 00^{\prime \prime}$ e $48^{\circ} 33^{\prime} 30^{\prime}$ "de longitude Oeste (Lapolli et al., 1990, apud NEMAR, 1999), sendo que o espelho d'água da Lagoa compreende uma área de $5,07 \mathrm{~km}^{2}$ (Silva, 2000). A Lagoa possui profundidade média de $2 \mathrm{a} 4 \mathrm{~m}$, atingindo $11 \mathrm{~m}$ na parte mais profunda. Encontra-se $3 \mathrm{~m}$ acima do nível do mar, não sofrendo influência das marés, sendo assim um dos principais reservatórios de água doce da costa catarinense e fonte de abastecimento da população do sul da ilha (Caruso, 1983, apud Silva, 2000).

O corpo lacunar é limitado a oeste por uma topografia acidentada, com altitudes de até $500 \mathrm{~m}$ e isolado do oceano, sendo e classificado como de água doce (NEMAR, 1999). De acordo com Simonassi (2001) os principais tributários para a bacia são os rios Ribeirão Grande e Cachoeira Grande, sendo que a água excedente escoa pelo canal "sangradouro" que desemboca no mar. O volume da Lagoa é regulado pelo regime pluviométrico que atua na bacia. O Ribeirão Grande e Cachoeira Grande s drenam uma área total de $8,64 \mathrm{~km}^{2}$, representando mais de $50 \%$ da área da bacia (exceto a área referente ao corpo lacunar). Essa realidade reflete a importância destes rios na manutenção do fluxo e aporte de água na Lagoa do Peri (Simonassi, 2001).

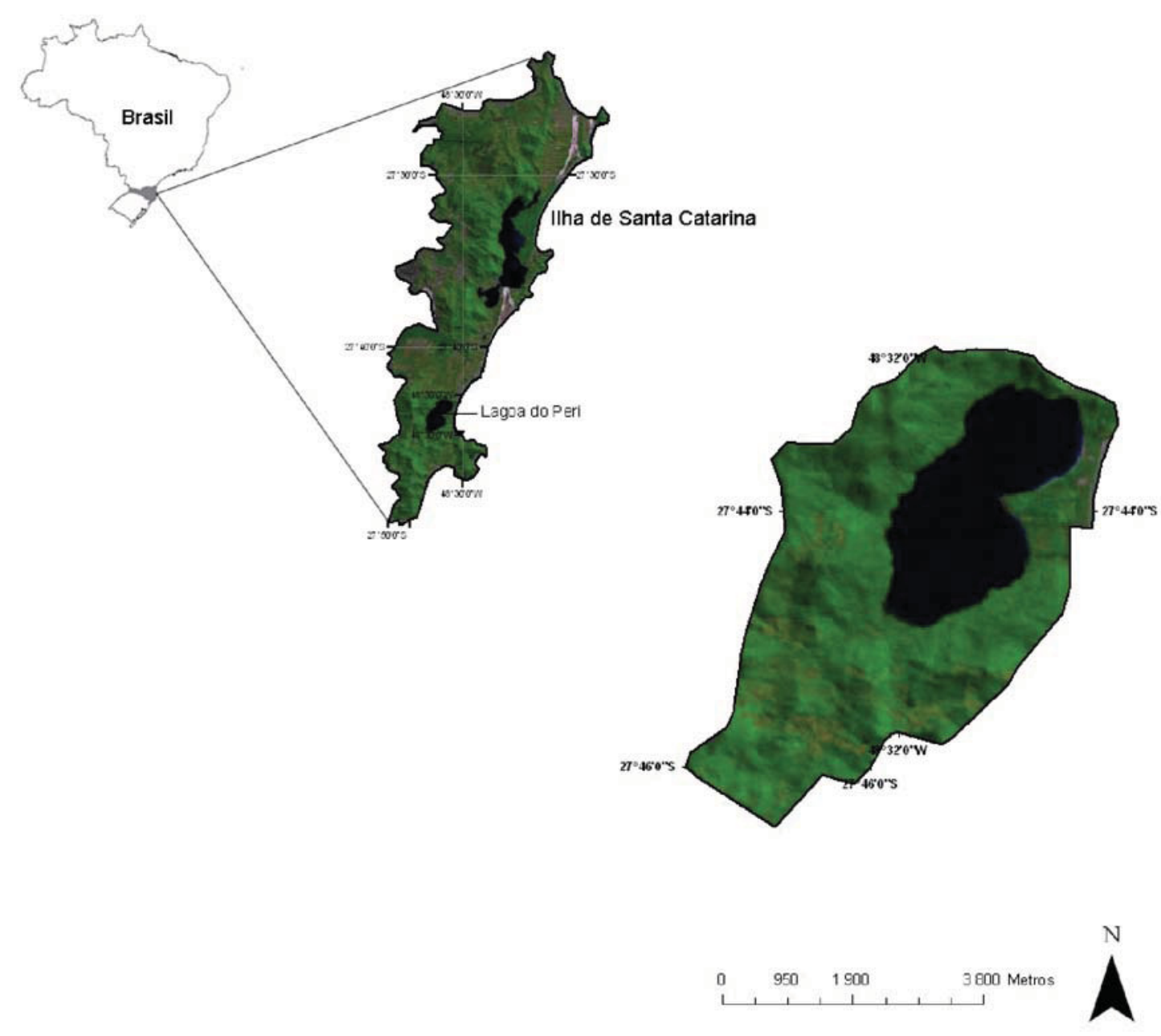

FIGURA 1: Localização da bacia hidrográfica da Lagoa do Peri na Ilha de Santa Catarina, cidade de Florianópolis, Santa Catarina, Brasil. 
O Parque Municipal da Lagoa do Peri apresenta-se, segundo o plano diretor do município, subdividido em três áreas cada qual com a descrição de uso e atividades permitidas (CECCA, 1997). 1) A Área de Reserva Biológica engloba a Floresta Pluvial de Encosta Atlântica e a vegetação Litorânea; 2) Área de Paisagem Cultural é onde se localizam os assentamentos e atividades tradicionais como engenhos de farinha e de cana-de-açúcar; 3) Área de Lazer, que corresponde à área da restinga e do corpo lacunar (Silva, 2000).

Atualmente, além de práticas como turismo, recreação, pesquisa e lazer, a Lagoa do Peri vem sendo utilizada como fonte de captação da Estação de Tratamento da Água, cujo órgão responsável é a Companhia Catarinense de Águas e Saneamento (CASAN), com a finalidade de abastecer com água potável a comunidade local e do leste e sul da Ilha de Santa Catarina.

\section{Levantamento de dados}

Neste trabalho foram realizadas pesquisas bibliográficas utilizando a palavra chave "Lagoa do Peri". Foram analisados todos os tipos de trabalhos que foram encontrados com este parâmetro (no título, resumo, e corpo do texto) e foram considerados apenas os que continham dados sobre a ecologia da Lagoa do Peri. A principal fonte foi a Biblioteca Universitária da Universidade Federal de Santa Catarina, onde foram pesquisados livros, monografias, teses e dissertações. Além disso, foram realizadas buscas nas seguintes bases de dados: i: Sistema Pergamun da biblioteca da UFSC (foram encontrados na busca 29 registros); ii: Sistema Scopus (encontrado um registro); iii: sistema Web of Science (encontrados 0 registros); iv: portal Scielo (encontrados dois registros). Nas referências bibliográficas estão listados todos os trabalhos utilizados.

\section{Resultados e Discussão}

Rios, riachos, sua bacia de drenagem, assim como a porção territorial, estão intimamente relacionados entre si, formando uma unidade, onde um ambiente tem influência direta sobre o outro e ambos se complementam. Alterações no ambiente terrestre do entorno da bacia hidrográfica, na vegetação ripária, nos fatores físicos do ambiente (ex. temperatura, oxigênio, luminosidade), resultarão em mudanças quanto aos aportes à Lagoa e conseqüentemente influenciarão direta ou indiretamente nas comunidades biológicas presentes na Lagoa, refletindo na qualidade ambiental do corpo aquático. Assim, uma compreensão precisa da ecologia da Lagoa do Peri requer que consideremos os rios e sua bacia de drenagem como uma unidade.

Um estudo pioneiro foi o realizado por Poli et al. (1978, apud NEMAR, 1999) no que diz respeito a características físico-químicas e biológicas da Lagoa do Peri, e consistiu em uma amostragem intensiva fornecendo dados para o planejamento do uso da Bacia. Esse estudo forneceu os dados sobre a fauna ictiológica, carcinológica, plâncton e bentônica, dados abióticos como pH, temperatura, salinidade, teor de oxigênio dissolvido, além de determinar a batimetria e sedimentologia do fundo da Lagoa.

A partir desse primeiro levantamento, outros estudos têm sido realizados na Lagoa do Peri, mas a maioria deles se concentra apenas na análise dos parâmetros físico-químicos da água, poucos incluem os parâmetros biológicos, e quando incluem referem-se mais à comunidade fitoplanctônica e ictiológica, pouco se conhecendo sobre as demais comunidades. Além disso, é necessário que esses dados sejam relacionados e interpretados com uma visão de ecologia sistêmica, levando em consideração interações entre populações e comunidades, fluxo de energia e ciclagem de nutrientes na bacia hidrográfica, podendo desta forma, obter-se dados mais precisos sobre a dinâmica do ecossistema, e contribuir para a manutenção e conservação do mesmo.

\section{Dados abióticos}

Levantamentos batimétricos da Lagoa do Peri (NEMAR, 1999; Simonassi, 2001) revelaram que a mesma é simétrica em suas margens laterais, com taludes relativamente íngremes próximos às margens, em seus extremos NE e SW a Lagoa apresenta áreas mais suaves e no centro ela é relativamente plana. Segundo Dutra (1999, apud NEMAR, 1999), os sedimentos da Lagoa, foram classificados em orgânicos; constituídos 
por grãos de silte e argila depositados no corpo d'água via escoamento superficial e por compostos orgânicos alóctones e em minerais, sendo dois os tipos: areia quartzosas retrabalhadas de origem quaternária, acumuladas em diversos ambientes deposicionais (marinho e de encosta e terraços lacunares antigos) e areias terrígenas imaturas, compostas de grãos minerais provenientes da desagregação e decomposição de rochas do complexo cristalino, que circunda grande parte da Lagoa.

Segundo Oliveira (2002), as condições morfo-sedimentares distribuem-se em dois setores distintos na Lagoa, um apresenta sedimentos granulosos e arenosos em profundidades que variam entre 0 a $3,5 \mathrm{~m}$ e o segundo setor com profundidades até $11 \mathrm{~m}$, que cobre todo o interior da Lagoa e possui sedimentos lamosos (sílticoargiloso e argilo-siltosos), associados a altos teores de matéria orgânica. O sedimento de ecossistemas aquáticos é o substrato responsável pela disponibilidade de hábitats e microhábitats, alimentos e proteção, exercendo um papel importante na estruturação das comunidades de macroinvertebrados bentônicos (Callisto et al., 2006). Segundo Callisto e Esteves (1996), a composição e distribuição dos sedimentos são fatores importantes na determinação dos padrões de distribuição de organismos e na estrutura de comunidades de macroinvertebrados bentônicos.

A caracterização do sedimento da Lagoa é fundamental para a análise do recurso hídrico, uma vez que nele ocorrem processos biológicos, físicos e/ou químicos que influenciam no metabolismo do ecossistema. Porém, há uma carência de estudos neste compartimento, sendo necessário um acompanhamento temporal, pois a dinâmica do entorno influencia diretamente no corpo d'água e no sedimento. Desta forma, alterações nesse podem implicar em mudanças no fluxo de nutrientes e na estruturação e dinâmica das comunidades presentes no corpo d'água.

Lamotte et al. (1999, apud NEMAR, 1999) detectou selênio no sedimento da Lagoa, e afirma que mais de $70 \%$ das espécies desse elemento encontram-se presentes como inorgânicas refratárias e de fraca biodisponibilidade. O selênio constitui um elemento essencial, mas de acordo com a sua concentração tem potencial tóxico. No caso da Lagoa do Peri, o autor concluiu que sua presença no sedimento (10 vezes maior do que a concentração elementar) e na água de superfície $(<0,5-1 \mu \mathrm{g} / \mathrm{L})$ parece não ser problema para a biota nem para fins de consumo humano. Porém, o autor ressalta que a presença inócua de selênio na Lagoa requer uma análise mais detalhada e um monitoramento em longo prazo da especiação do elemento e sobre seu potencial de bioacumulação.

Temperaturas máximas na água em torno de $30^{\circ} \mathrm{C}$ (janeiro/97) e mínima de $15^{\circ} \mathrm{C}$ (junho/96) foram determinadas por Laudares-Silva (1999). Simonassi (2001) analisou o perfil de temperatura na coluna d'água $(9 \mathrm{~m})$ que apresentou na maioria dos meses uma variação de apenas $0,5^{\circ} \mathrm{C}$, indicando uma homotermia da coluna. Apenas nos meses de outubro/98 e fevereiro/99, foi registrada uma variação de $1,5^{\circ} \mathrm{Ce} 2^{\circ} \mathrm{C}$ respectivamente da temperatura na coluna d'água. Esses dados ainda não são suficientes para definir o padrão de circulação da Lagoa, mas sabe-se que a pouca profundidade, juntamente com a constante circulação da água causada pela ação dos ventos, impossibilitam o processo de estratificação.

Os maiores valores de transparência (1m) encontrados na Lagoa foram registrados em março de 98 e o menor em abril do mesmo ano $(0,5 \mathrm{~m})$. Os valores baixos de transparência podem estar associados a um aumento do crescimento das algas no corpo aquático o que requer maiores estudos sobre a comunidade fitoplanctônica da Lagoa e sua relação com o entorno (Simonassi et al., 1999, apud NEMAR 1999).

Os perfis de oxigênio dissolvido revelaram uma tendência à redução dos valores em direção ao fundo, não apresentando deficiência de oxigênio e mais homogeneidade (Laudares-Silva, 1999; Simonassi, 2001). As concentrações variaram entre 7,6 e $12 \mathrm{mg} / \mathrm{L}$, no verão e inverno, respectivamente. Fato explicado pela intensa ação dos ventos que agem sobre a Lagoa, que provocam uma constante circulação na coluna d'água, fazendo com que o oxigênio se distribua ao longo da coluna, não ocorrendo regiões anóxicas. Outra importante fonte é o processo fotossintético devido à presença de comunidades fitoplanctônicas que ocorre em boa parte da coluna d'água.

Dados sobre a oxigenação da Lagoa são de fundamental importância, porque estão relacionados com a 
biodiversidade presente no ambiente. Quanto maiores as taxas de oxigênio e mais distribuídas na coluna d'água maior serão as chances de comunidades mais complexas e diversificadas se adaptarem (Esteves, 1988). O papel da diversidade está estreitamente ligado às estruturas de redes dos sistemas. Por conter muitas espécies com funções biológicas sobrepostas que podem substituir umas às outras, o ecossistema diversificado é capaz de se recuperar rapidamente à perturbações externas (Begon et al. 2007). Quanto mais complexos forem os padrões de interconexão da rede, mais rapidamente e maiores serão as chances de sobrevivência, reorganização e recuperação destas comunidades, permitindo assim um bom funcionamento dos ciclos ecológicos e a sustentação do ecossistema.

Os valores de condutividade elétrica e $\mathrm{pH}$, variaram entre 70 e $180 \mu \mathrm{S} / \mathrm{cm}$ e 6,5 a 8,1 respectivamente (Laudares-Silva, 1999; NEMAR 1999; Simonassi, 2001). Isso pode ser explicado também pela ação dos ventos na região, que acaba gerando um aporte de compostos ionicamente carregados provenientes do spray marinho, bem como pela interferência das precipitações marinhas, que segundo Esteves (1988), carregam mais íons $\mathrm{Na}^{+}$, $\mathrm{Mg}^{2+} \mathrm{e} \mathrm{Cl}^{-}$do que as precipitações terrestres. A leve tendência à alcalinidade, provavelmente, é resultante de compostos tamponantes como carbonatos e bicarbonato também provenientes do spray marinho.

O monitoramento regular desses parâmetros é de suma importância, pois se tratando de um corpo aquático com finalidades de abastecimento, esses valores devem manter-se aproximadamente neutros, o que caracteriza a água como sendo própria para o consumo humano e que também favorece a biodiversidade das comunidades aquáticas.

De acordo com Carmouze (1994), elevados índices de nutrientes como nitrato, nitrito e fosfato, funcionam como indicadores de meio poluído, demonstrando um estado avançado de eutrofização. Nitrogênio e fósforo são elementos essenciais para a existência e para o metabolismo das comunidades aquáticas, sendo que o acúmulo desses nutrientes nas águas indica freqüentemente mudanças repentinas na densidade da comunidade planctônica, enquanto que a diminuição das concentrações de nutrientes pode ser resultado do desenvolvimento brusco do fitoplâncton (Carmouze, 1994).
A Lagoa do Peri apresentou baixas e poucas variações de concentrações de nitrito e nitrato (Laudares-Silva, 1999; Simonassi et al., 1999, apud NEMAR, 1999; Simonassi, 2001), sendo as máximas concentrações obtidas de 0,21 e de $0,8 \mu \mathrm{M} / \mathrm{L}$ respectivamente. As concentrações de fosfato variaram de 0 a $0,84 \mu \mathrm{M} / \mathrm{L}$, apresentando uma diminuição nos meses mais quentes e aumento na sua concentração durante os meses mais frios (Simonassi, 2001), o que segundo o autor está relacionado com a quantidade de clorofila a na Lagoa, que é aumentada no verão, aumentando também a atividade fitoplanctônica e conseqüentemente o consumo desses nutrientes pela comunidade. Assim os nutrientes passam de sua forma dissolvida para particulada, tornando-se menos disponível no corpo aquático. O contrário ocorre no inverno, quando as taxas de clorofila a são menores.

No que se refere ao material de suspensão da Lagoa, o sêston teve sua máxima e mínima concentração respectivamente em setembro e outubro de 98 (16,8 e 3,2mg/L) (NEMAR, 1999; Simonassi, 2001). Fatores que têm influência direta nesse parâmetro são os ventos, que ressuspendem o material particulado depositado no fundo, e as chuvas, que carregam maior quantidade de detritos e sedimentos finos para dentro da Lagoa. De acordo com estes autores e com Laudares-Silva (1999), percebe-se que há no geral um predomínio da porção de matéria orgânica no sêston sobre a porção de matéria inorgânica, com médias máximas de $6,22 \mathrm{mg} / \mathrm{L}$ e $1,98 \mathrm{mg} / \mathrm{L}$, respectivamente.

\section{Dados bióticos}

Análises de clorofila a em corpos d'água são necessárias, pois fornecem, de uma forma aproximada, dados sobre a produtividade primária tanto do fitoplâncton quanto de macrófitas aquáticas (Simonassi, 2001). Esse parâmetro, de acordo com o autor, demonstrou um aumento nas suas concentrações nos meses mais quentes (novembro e dezembro de 1998) em que a intensidade luminosa foi maior, favorecendo o desenvolvimento das algas e conseqüentemente o aumento das concentrações de Clorofila a (média de 36,9 $\mu \mathrm{g} / \mathrm{L}$ ). Já no inverno, as baixas temperaturas e luminosidade desfavoreceram o desenvolvimento das algas diminuindo sua população, 
tendo uma média 15,89 $\mu \mathrm{g} / \mathrm{L}$ entre os meses de junho e setembro de 1998.

Sobre as comunidades aquáticas da Lagoa do Peri, os dados mais comuns são referentes ao fitoplâncton, que se distribuem em nove classes, sendo Cyanophyceae e Chlorophyceae as mais abundantes (Laudares-Silva, 1999). Estudos demonstram que desde 1996 tem-se observado a presença de algas potencialmente nocivas neste ecossistema (Laudares-Silva, 1999; NEMAR, 1999; Matthiensen e Barbosa, 2003; Grellmann, 2006). A espécie de cianobactéria Cylindrospermopsis raciborskii é dominante em densidade em relação às demais espécies, ocorrendo grandes florações (blooms) nos corpos d'água.

Esta espécie possui alto potencial de produzir cianotoxinas extremamente agressivas, as quais podem causar problemas de saúde pública e danos ao meio ambiente. No caso de mananciais para fins de captação de água, como a Lagoa do Peri, isso pode tornar-se um problema, uma vez que a morfologia, resistência química e flutuabilidade deste fitoplâncton permitem sua passagem através dos filtros de tratamento, sendo muito comum sua presença em águas a priori tratadas (Yunes, 2003). Além disso, a alta concentração de algas presentes na Lagoa colmatam os filtros da estação de tratamento, aumentando o consumo de água tratada utilizada na lavagem dos mesmos e no tempo das carreiras de filtração (Mondardo, 2004; Rabelo, 2006).

A presença de saxitoxina e derivados, em pequenas concentrações, foi registrada na água do Peri e pode ser atribuída à C. raciborskii (Grellmann, 2006). Matthiensen e Barbosa (2003) demonstraram também a presença da clorofícea Botryococcus sp. na Lagoa e recomendaram a realização de futuros monitoramentos do fitoplâncton como uma ferramenta importante no gerenciamento da água de corpos destinados ao consumo humano. Segundo estes autores, a ocorrência e concentração desses organismos, correlacionadas aos parâmetros ambientais, forneceriam dados referentes aos blooms dessas algas, permitindo que medidas preventivas fossem tomadas.

Tucci e Sant'Anna (2003) demonstraram que florações de C. raciborskii têm sido cada vez mais freqüen- tes em reservatórios brasileiros em virtude da sua alta competitividade em ambientes tropicais eutrofizados. Associaram também, que maiores densidades da espécie ocorreram durante o verão, com registros de estratificação, elevados valores de temperatura e turbidez da água e baixa transparência da água, já nos meses de outono e inverno ocorre o inverso, e associado a um aumento considerável dos bancos de macrófitas aquáticas.

Com relação ao Peri, estudos contínuos e em longo prazo sobre a produtividade primária e a dinâmica dessas populações algais, permitiriam diagnósticos sobre o grau de eutrofização do corpo d'água, bem como dados sobre os riscos que suas toxinas exercem sobre as demais comunidades e a população humana, corroborando com o manejo e a conservação do recurso aquático, garantindo a saúde do ecossistema e dos recursos que ele provê.

De acordo com Ribeiro (1999, apud NEMAR 1999), a Lagoa apresentou baixa densidade e diversidade de espécies zooplanctônicas. Foram registradas 18 espécies (quatro de cyclopodida, seis de cladocera e oito de rotífera), sendo Cladocera o grupo dominante, com cinco espécies ocorrendo durante maior parte do ano, sendo Bosmina hagmani a dominante. Baixas densidades desses organismos, segundo o autor podem ser devido ao método de coleta e também estar relacionados à alta densidade de C. raciborskii, observada durante o estudo e que não é utilizada como alimento pelo zooplâncton.

Apesar de haver um conhecimento razoável sobre a taxonomia das espécies de algas e macrófitas aquáticas, a sucessão dessas espécies e a diversidade dos agrupamentos sob diferentes condições tróficas, como ressaltado por Barbosa (1994), ainda necessitam de maiores estudos. Segundo o autor, a utilização isolada de parâmetros químicos para a identificação do estado trófico pode levar a interpretações errôneas nos ambientes com elevada biomassa de macrófitas, nos quais grandes fluxos de nutrientes podem ser absorvidos rapidamente provocando baixas concentrações na água.

De acordo com Soriano-Sierra e Berlinck (1999, apud NEMAR, 1999) na Lagoa do Peri, Scirpus californicus, conhecida popularmente como Peri, é a espécie de macrófita aquática mais abundante, sendo encontrada em todas as estações, crescendo sobre substrato arenoso, aluvial e orgânico. Ainda segundo o autor, a espécie 
ocorre nesta Lagoa desde locais que só são inundados quando o vento eleva o nível da água até a profundidade de 1,5m no interior do lago. Segundo Schultz (1990), a presença do gênero Scirpus é considerada sinal de acidez excessiva do solo.

Sobre a comunidade nectônica, o maior destaque é para a ictiofauna, mas sendo ainda carentes dados sobre a dinâmica e estrutura dessa comunidade, e sua relação trófica no ambiente aquático. Segundo Ribeiro (1999, apud NEMAR, 1999), 12 famílias foram identificadas, as de maior abundância são Cichlidae, Clupeidae e Characidae, conhecidas popularmente por manjubão, sardinha, traíra, lambari, jundiá, tainha, peixe-rei, barrigudinho, robalo, carapicú, cará, tilápia e maria da toca. Quanto à carcinofauna 3 famílias são conhecidas, Palaemonidae (pitu), Atyidae, Portunidae (siri-patóla). Porém esses levantamentos têm sido pontuais, concentrados apenas no corpo lacunar não levando em consideração a diversidade de espécies presentes nos tributários que deságuam na Lagoa, que alteram a dinâmica, estrutura e funcionamento da mesma.

Dados sobre a comunidade bentônica são praticamente inexistentes, demonstrando a carência de informações sobre esses organismos, fundamentais para a ciclagem de nutrientes, de importante papel ecológico. Por terem ciclo de vida relativamente longo e hábito séssil, esses registram o acúmulo de eventos ambientais, refletindo as condições do ambiente numa escala temporal, que varia de sazonal a anual. Podendo dessa forma, fornecer um parecer sobre a biodiversidade e qualidade dos ecossistemas onde são encontrados, tornando-se importantes bioindicadores da qualidade e dinâmica ambiental dos corpos d'água.

Por este motivo, o seu monitoramento torna-se mais eficiente que apenas a mensuração de parâmetros físicos e químicos (Callisto e Moreno, 2006). Através da análise do grupo funcional de alimentação dessa comunidade, é possível inferir sobre a qualidade do corpo d'água, uma vez que a forma e a composição da alimentação dessas comunidades reflete o tipo de material disponível no ambiente aquático, e se ele tem origem autóctone ou alóctone.

A vegetação que circunda a Lagoa é constituída basicamente por formações de Floresta Ombrófila Densa
(Soriano-Siera, 1999, apud NEMAR, 1999), ocupando áreas com diferentes estágios sucessionais representados por capoeirinhas, capoeiras e capoeirões decorrentes do abandono de áreas antes utilizadas para a agricultura; e também pela vegetação de restinga, nas porções mais à leste. A vegetação ripária forma corredores ao longo da bacia hidrográfica funcionando como valiosas fontes de energia para as comunidades biológicas, provendo hábitats e fluxo de energia para os ecossistemas terrestres e aquáticos. A quantidade e as espécies que compõem esse ecossistema podem afetar diretamente as características dos canais dos rios. $\mathrm{O}$ acúmulo de restos de vegetação oriundos da mata ciliar pode influenciar na distribuição do sedimento, retenção de matéria orgânica e nutrientes, e na formação de microhábitats, importantes para as comunidades de peixes e invertebrados aquáticos (FISRWG, 1998).

Modificações naturais e artificiais na cobertura vegetal das bacias hidrográficas influenciam seu comportamento hidrológico. Essas alterações produzem vários impactos sobre o meio ambiente e a disponibilidade dos recursos hídricos (Clarke e Tucci, 1998). A ocupação desordenada de uma bacia provoca grandes alterações na qualidade d'água, como a poluição gerada por atividades urbanas (efluentes domésticos e industriais) e o aporte de materiais que alteram a dinâmica do ambiente aquático.

Especial atenção para o potencial de risco nas faixas de mata ciliares e nas formações vegetais naturais ocorrentes ao longo da rede de drenagem é recomendável para a Lagoa do Peri, pois essas áreas auxiliam na contenção da descarga de sedimento e resíduos alóctones além de controlarem o regime hídrico. Barbosa (1994) sugere o estabelecimento de uma rede de monitoramento físico, químico e biológico detalhada, para identificar os locais sujeitos à poluição e que não seriam identificados através de simples análises químicas. Também para o autor a variação regional das espécies deve ser levada em conta, quando se tratarem de espécies indicadoras.

Devido à importância ecológica, econômica e social dos ambientes aquáticos continentais, a proteção de suas bacias de drenagem, ou parte delas, pode melhorar as suas características ecológicas como um todo. Áreas protegidas podem ser de fundamental importância para 
a preservação dos ecossistemas aquáticos continentais e conseqüentemente dos organismos aquáticos que neles vivem, além da possibilidade de serem utilizadas como áreas de referência, permitindo a avaliação da qualidade ambiental da bacia hidrográfica ao compará-las com as demais áreas (Calllisto e Moreno 2006). Assim, um entendimento amplo sobre o entorno da Lagoa e da bacia de drenagem, tornam-se fundamentais para uma boa análise ambiental, e consequentemente para ações de conservação desse patrimônio, essencial para a sustentação da vida nas suas mais diversas formas.

\section{As principais necessidades}

O Parque Municipal da Lagoa do Peri é uma unidade de conservação que permite usos múltiplos, mas para que esse uso se sustente até gerações futuras é necessário que a capacidade de suporte dos ambientes (rios, lagoa, restinga) seja respeitada. Estudos realizados na área, aliados à conscientização ambiental, são uma ferramenta de cunho científico com fim sócio-econômico e ambiental importante. Tendo como base a atual conjuntura da civilização humana, onde recursos naturais, como a água, são cada vez mais escassos e menos disponíveis, percebe-se a necessidade de haver mudanças no paradigma sócio-econômico, para o modelo sócioeconômico e ambiental, pois somente com a integração desses setores poder-se-á chegar a soluções concretas e eficientes nas mais variadas esferas.

Tratando-se de um dos principais mananciais de água doce da Ilha de Santa Catarina, a Lagoa do Peri deve ser compreendida como um ecossistema complexo e ao mesmo tempo frágil. Um patrimônio natural que agrega muitos valores, cuja proteção deve ser de suma prioridade. Impedir a contaminação de fontes de água potável além de manter a integridade dos ecossistemas é fundamental para manutenção da saúde pública, uma vez que diminui os gastos com tratamento de água e de doenças veiculadas a ela.

A bacia do Peri necessita de estudos com uma abordagem de ecologia sistêmica e de longa duração, no que diz respeito à produtividade do corpo aquático, variação da temperatura, do oxigênio e os padrões de ciclagem de nutrientes, a influência da vegetação ripária na área de dre- nagem da Lagoa, e principalmente acerca da dinâmica das comunidades biológicas aquáticas. Há carência de dados sobre a estrutura e funcionamento do plâncton e do bentos, fundamentais para análise da relação de autrofia/heterotrofia dos corpos aquáticos. Outros microorganismos também são referenciados como suporte a estudos da qualidade de água, destacando a relevância de estudos que contemplem a diversidade microbiana. É necessário maior conhecimento e entendimento sobre as comunidades, quais são elas, como se estruturam, como se relacionam entre si e com o entorno, como reagem a diferentes fatores abióticos, qual a influência desses na dinâmica do ecossistema e como eles variam ao longo do ano.

Sugere-se a implantação de programas de biomonitoramento ambiental baseados na correlação de parâmetros físico-químicos e biológicos, onde inventários taxonômicos das comunidades aquáticas podem ser descritos com a finalidade de avaliar a saúde ambiental e integridade biológica dos recursos hídricos. Através destas informações, poderão ser estabelecidas áreas prioritárias para conservação e áreas passíveis de serem utilizadas, desde que sustentavelmente. Partindo dessa problemática, percebe-se a necessidade de haver práticas educacionais, políticas e sociais aliadas a práticas ambientais conservacionistas, voltadas para o manejo e uso sustentável da bacia da Lagoa. O plano de manejo do parque deve ser elaborado de forma participativa, envolvendo a comunidade, academia, e demais setores envolvidos, atendendo às necessidades sociais e ambientais e garantindo assim a qualidade e disponibilidade do recurso para estas e futuras gerações.

Um incentivo para pesquisas científicas deve partir dos órgãos públicos e/ou de parcerias público-privadas, pois ainda há muito que ser feito, principalmente no que diz respeito à bacia hidrográfica e suas comunidades aquáticas, que vêm sofrendo muito com o uso inadequado. Espera-se também maior envolvimento, planejamento e investimento por parte dos órgãos públicos ambientais, com fiscalização mais efetiva sobre o uso dos recursos naturais que o parque dispõe. Sugere-se que um banco de dados seja criado, reunindo os mais diversos dados já levantados sobre o Parque Municipal da Lagoa do Peri, e que estes, extrapolem a comunidade científica, atingindo a sociedade, principalmente a comunidade 
local. Concomitantemente, práticas educacionais de conscientização sócio-ambiental devem ser realizadas continuamente com a comunidade, com o intuito de sensibilizá-la para o uso adequado e sustentável do Parque. Por fim, os órgãos responsáveis devem avaliar o gerenciamento do parque, juntamente com a comunidade, a fim de encontrarem alternativas econômicas, sociais e ecologicamente viáveis, podendo dessa forma preservar o local e conservar a qualidade de vida, nas suas mais diversas formas.

\section{Agradecimento}

Os autores agradecem ao Dr. André Luiz dos Santos Furtado, pesquisador da Empresa Brasileira de Pesquisa Agropecuária (Embrapa - CNPM) pela elaboração da figura 1.

\section{Referências}

Barbosa, F. A. R. (ed.) 1994. Workshop: Brazilian programme on conservation and management of inland waters. v. 5. Acta Limnologica Brasiliensia, Sociedade Brasileira de Limnologia, Belo Horizonte, Brazil, 222pp.

Barbosa, F. A. R.; Callisto, M.; Galdean, N.; Rocha, L. A. 2000. Lotic ecosystems of Serra do Cipó, southeast Brazil: water quality and a tentativa classification based on the benthic macroinvertebrate community. Journal Aquatic Ecosystem Health \& Management, 3: 545-552.

Barbour, M. T.; Gerritsen, J.; Snyder, B. D.; Stribling, J. D. 1999. Rapid bioassessment protocols for use in streams and wadeable rivers. Periphyton, benthic macroinvertebrates and fish. $2^{\text {nd }} \mathrm{ed}$. EPA, U.S. Environmental Protection Agency; Office of Water; Washington, USA, 339pp.

Begon, M.; Townsend, C.; Harper, J. 2007. Ecologia: de indivíduos a ecossistemas. Editora Artmed, Porto Alegre, Brasil, 752pp.

Callisto, M.; Esteves, F. A. 1996. Composição granulométrica do sedimento de um lago Amazônico impactado por rejeito de bauxita e um lago natural - Pará, Brasil. Acta Limnologica Brasiliensia, 8: $115-126$.

Callisto, M.; França, J. S.; Moreno, P. 2006. Importância da composição granulométrica para a comunidade bentônica e sua relação com o uso e ocupação do solo na Bacia Hidrográfica do Rio das Velhas (MG). Anais do VII Encontro Nacional de Engenharia de Sedimentos, Porto Alegre, Brasil, p.12.

Callisto, M.; Moreno, P. 2006. Bioindicadores como ferramenta para o manejo, gestão e conservação ambiental. Anais $\mathbf{I I}^{\mathbf{0}}$ Simpósio Sul de Gestão e Conservação Ambiental, Erechim, Brasil, p.206.

Carmouze, J. P. 1994. O metabolismo dos ecossistemas aquáticos : fundamentos teóricos, métodos de estudo e análises químicas. Edgard Blücher, FAPESP, São Paulo, Brasil, 253pp.
CECCA, Centro de Estudos Cultura e Cidadania. 1997. Unidades de Conservação e Áreas Protegidas da Ilha de Santa Catarina: caracterização e legislação. Ed. Insular, Florianópolis, Brasil, 160pp.

Clarke, R. T.; Tucci, C. E. M. 1998. Impacto das mudanças da cobertura vegetal no escoamento: revisão. Anais I Fórum Geo-BioHidrologia: Estudos em vertentes e microbacias hidrográficas, Curitiba, Brasil, p.237.

Esteves, F. A. 1988. Fundamentos de Limnologia. Interciência, FINEP, Rio de Janeiro, Brasil, 575pp.

FISRWG. 1998. Stream corridor restoration: Principles, processes, and practices. By the Federal Interagency Stream Restoration Working Group (FISRWG) (15 Federal agencies of the US government), 653pp.

Grellmann, C. 2006. Aspectos da morfologia e ecologia de Cylindrospermopsis raciborskii (Woloszinska) Seenayya et Subba Raju e produção de cianotoxinas na Lagoa do Peri, Florianópolis, SC, Brasil. Dissertação de Mestrado, Universidade Federal de Santa Catarina,Florianópolis, Brasil, 94pp.

Laudares-Silva, R. 1999. Aspectos limnológicos, variabilidade espacial e temporal na estrutura da comunidade fitoplanctônica da Lagoa do Peri, Santa Catarina, Brasil. Tese de Doutorado, Universidade Federal de São Carlos, São Carlos, Brasil, 220pp.

Matthiensen, A.; Barbosa, T. C. P. 2003. Fitoplâncton potencialmente nocivo em corpos d'água costeiros utilizados para o consumo humano: dados preliminares da Lagoa do Peri, Florianópolis, SC. Anais do IX Congresso Brasileiro de Limnologia, Juiz de Fora, Brasil, CD Rom.

Mondardo, R. I. 2004. Influência da pré-oxidação na tratabilidade das águas via filtração direta descendente, em manancial com elevadas concentrações de microalgas e cianobactérias. Dissertação de Mestrado, Universidade Federal de Santa Catarina, Florianópolis, Brasil, 147pp.

NEMAR, 1999. Diagnostico ambiental visando um programa de monitoramento da Lagoa do Peri, Ilha de Santa Catarina, SC. v. I e II. Programa Institucional de Estudo de Sistemas Costeiros - PIESC, Universidade Federal de Santa Catarina, Florianópolis, Brasil, 286pp.

Oliveira, J. S. de. 2002. Análise sedimentar em zonas costeiras: subsídio ao diagnóstico ambiental da Lagoa do Peri - Ilha de Santa Catarina-SC, Brasil. Dissertação de Mestrado, Universidade Federal de Santa Catarina, Florianópolis, Brasil, 154pp.

Penteado, A. N. 2002. Subsídios para o plano de manejo do Parque Municipal da Lagoa do Peri - Ilha de Santa Catarina, Florianópolis - SC. Dissertação de Mestrado, Universidade Federal de Santa Catarina, Florianópolis, Brasil, 128pp.

Pereira, M. A. 2001. Diagnóstico físico e socioambiental do Parque Municipal da Lagoa do Peri subsídios ao Plano de Manejo. Dissertação de Mestrado, Universidade Federal de Santa Catarina, Florianópolis, Brasil, 243pp.

Rabelo, L. P. 2006. Estudos preliminares para implantação da filtração em margem na Lagoa do Peri como pré-tratamento de água para remoção de fitoplâncton. Dissertação de Mestrado, Universidade Federal de Santa Catarina, Florianópolis, Brasil, 152pp. 
Santa Catarina. 1997. Bacias hidrográficas de Santa Catarina: diagnóstico geral. Secretaria de Estado do Desenvolvimento Urbano e Meio Ambiente, Florianópolis, Brasil, 163pp.

Silva, A. Á. de S. da. 2000. Parque Municipal da Lagoa do Peri subsídios para o gerenciamento ambiental. Dissertação de Mestrado, Universidade Federal de Santa Catarina, Florianópolis, Brasil, 120pp.

Simonassi, J. C. 2001. Caracterização da Lagoa do Peri, através da análise de parâmetros físico-químicos e biológicos, como subsídio ao gerenciamento dos recursos hídricos da Ilha de Santa Catarina, SC, Brasil. Dissertação de Mestrado, Universidade Federal de Santa Catarina, Florianópolis, Brasil, 72pp.
Schultz, A. 1990. Introdução à botânica sistemática. v. 2. $6^{\mathrm{a}}$ ed. Ed. Sagra, Porto Alegre, Brasil, 140pp.

Tucci, A.; Sant'Anna, C. L. 2003. Cylindrospermopsis raciborskii (Woloszynska) Seenayya \& Subba Raju (Cyanobacteria): variação semanal e relações com fatores ambientais em um reservatório eutrófico, São Paulo, SP, Brasil. Revista Brasileira de Botânica, 26 (1): 97-112.

Yunes, J. S. 2003. Programa AGUAAN - Agilização do gerenciamento e utilização de águas com algas nocivas. Biológico, 65 (1/2): 117-119. 